TABLE 1. Residual air emboli 10 minutes after termination of CPB $(n=20)$

\begin{tabular}{|c|c|c|c|c|c|c|c|c|}
\hline \multirow{3}{*}{$\begin{array}{c}\text { Minutes after } \\
\text { termination of CPB }\end{array}$} & \multicolumn{4}{|c|}{ Study group $(n=10)$} & \multicolumn{4}{|c|}{ Control group $(n=10)$} \\
\hline & \multicolumn{4}{|c|}{$\mathbf{N}$} & \multicolumn{4}{|c|}{$\mathbf{N}$} \\
\hline & Grade* 0 & Grade I & Grade II & Grade III & Grade 0 & Grade I & Grade II & Grade III \\
\hline $0-3$ & 1 & 8 & 1 & 0 & 1 & 0 & 1 & 8 \\
\hline $4-6$ & 9 & 0 & 1 & 0 & 0 & 4 & 5 & 1 \\
\hline $7-10$ & 9 & 1 & 0 & 0 & 2 & 3 & 4 & 1 \\
\hline
\end{tabular}

$C P B$, Cardiopulmonary bypass. *Transesophageal echocardiographic 3-chamber view: grade 0, no residual air emboli; grade I, air emboli observed in 1 of the 3 chambers (left atrium, left ventricle, and aortic root) during 1 cardiac cycle; grade II, air emboli observed simultaneously in 2 of the 3 chambers during 1 cardiac cycle; grade III, air emboli observed simultaneously in all 3 chambers during 1 cardiac cycle.

completely, with blood flushing all entrapped air within them. Successive increase in the right ventricular preload coupled with a delayed and staged increase in the minute volume ventilation maintains the pulmonary veins free from air until the patient is completely weaned from CPB.

In conclusion, the deairing technique reported here is simple, reproducible, controlled, safe, and effective. Moreover, it is cost-effective because the deairing time is short, and no extra expenses are involved.

\section{References}

1. Komukai K, Hirooka K, Taneike M, Yasuoka Y, Yamamoto H, Hashimoto K, et al. ST elevation during open heart surgery-floating air bubble in saphenous vein graft. Images in cardiovascular medicine. Circulation. 2005;111:e374.

2. Abu-Omar Y, Cifelli A, Matthews PM, Taggart DP. The role of microembolisation in cerebral injury as defined by functional magnetic resonance imaging. Eur $J$ Cardiothorac Surg. 2004;26:586-91.

3. Tingleff J, Joyce FS, Pettersson G. Intraoperative echocardiographic study of air embolism during cardiac operations. Ann Thorac Surg. 1995;60:673-7.

4. Svenarud P, Persson M, van der Linden J. Effect of CO2 insufflation on the numbe and behavior of air microemboli in open-heart surgery: a randomized clinical trial. Circulation. 2004;109:1127-32.

\title{
Thoracic esophagostomy: A novel surgical approach for preservation of esophageal length for use in subsequent reconstruction
}

\author{
Craig R. Moores, BA, and Darroch Moores, MD, Albany, NY
}

We report two cases of end thoracic esophagostomy. This novel approach can be utilized to preserve esophageal length for reanastomosis in secondary reconstruction.

\section{CLINICAL SUMMARY \\ Patient 1}

The first patient was a newborn male patient with necrosis of the stomach, colon, and small bowel due to maternal abuse of crack cocaine. At 24 hours of age, the infant underwent total gastrectomy, right hemicolectomy, and subtotal small bowel resection. Due to intraoperative instability, reconstruction was delayed. An end esophageal thoracic

\footnotetext{
From the Albany Medical College, Albany, NY

Received for publication Sept 4, 2008; accepted for publication Sept 27, 2008; available ahead of print May 11, 2009.

Address for reprints: Darroch Moores, MD, Albany Medical College, Department of Thoracic Surgery, 43 New Scotland Ave, Albany, NY 12208 (E-mail: dmoores1@ nycap.rr.com).

J Thorac Cardiovasc Surg 2009;138:1439-41

$0022-5223 / \$ 36.00$

Copyright (c) 2009 by The American Association for Thoracic Surgery

doi:10.1016/j.jtcvs.2008.09.054
}

esophagostomy was performed posteriorly through a resected portion of the 10th rib, just lateral to the paraspinal muscles (Figure 1,A). The infant was then allowed to grow and stabilize for 3 months with a feeding jejunostomy. At 3 months, the esophagostomy was taken down and the infant was reconstructed. The midtransverse colon was isolated as used with an end-to-side esophagocolostomy and a Roux-en-Y jejunocolostomy (Figure 1, B). Subsequently, he has done well and thrived.

\section{Patient 2}

The second patient was a 78-year-old woman with severe coronary artery disease, diabetes, and chronic renal failure, who underwent laparoscopic repair of a massive hiatal hernia at an outside institution. A polytetrafluoroethylene patch was used in the hiatus. The patient developed a postoperative gastric fistula, a subphrenic abscess, and sepsis. The subphrenic abscess was drained percutaneously; she was stabilized and transferred to our hospital.

Subsequently, the patient developed an undilatable stricture at the gastroesophageal junction. At 4 weeks following 


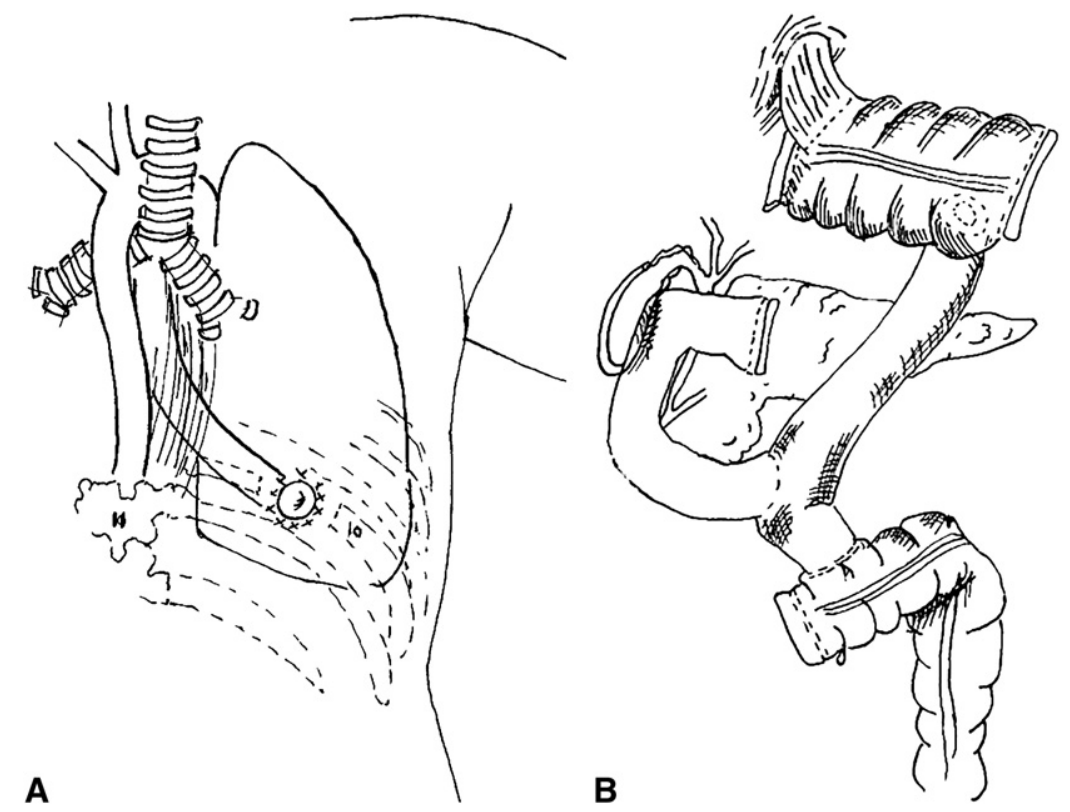

FIGURE 1. A, Posterior view of a thoracic esophagostomy in an infant. The esophagus was taking out through a resected portion of the 10th rib. B, Esophagocolostomy and Roux-en-Y jejunocolostomy secondary reconstruction of the infant was performed in this manner.

her original surgery, she was taken back to the operating room, and a thoracolaporotomy was performed. At surgery, she was found to have gross puss in the subphrenic space, as well as a shrunken, grossly thickened, ischemic stomach. The polytetrafluoroethylene patch was removed. The stomach was deemed nonsalvageable and therefore a total gastrectomy was performed. Primary reconstruction was not carried out due to the local sepsis. We elected to perform an end thoracic esophagostomy at the 10th rib posteriorly to preserve esophageal length. The patient was allowed to recover for 3 months with a feeding jejunostomy. At 3 months, she had a redo thoracolaporotomy. The esophageal stoma was taken down, and the small bowel was anastomosed to the jejunum as an Roux-en-Y esophagojejunostomy.

\section{DISCUSSION}

The described intraoperative technique is useful to preserve esophageal length for subsequent reconstruction. Esophageal reconstruction is always challenging, and deciding which approach to take is often debated. It is our belief that, if possible, a patient's native esophagus is preferred for both primary and secondary reconstruction in situations involving benign esophageal disease.

In the case of the infant, we were faced with a situation where there was very little gut, other than the native esophagus, for secondary reconstruction. The challenge was to find a way to preserve esophageal length while allowing the child to grow prior to reconstruction.

In the second case, we present an elderly patient with multiple comorbidities who had gross sepsis, thereby prohibiting primary reconstruction. Due to the risks associated with total

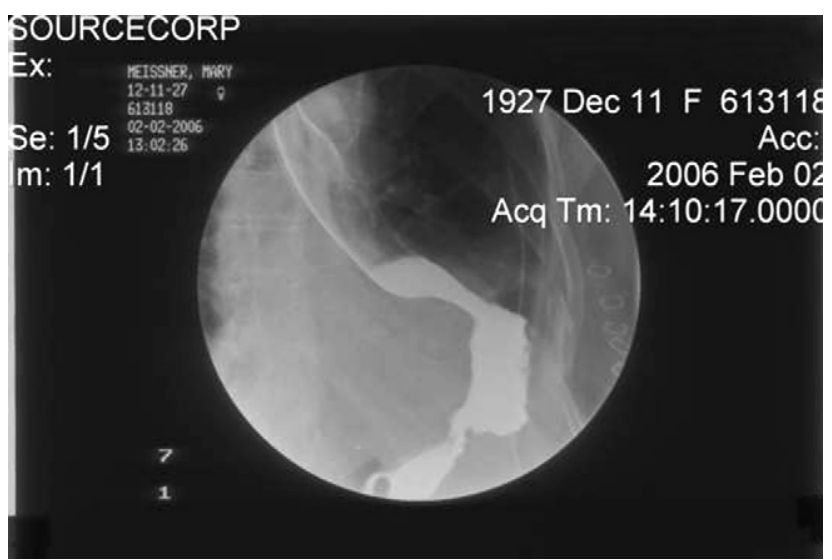

FIGURE 2. Barium esophagram after Roux-en-Y esophagojejunostomy (patient 2).

thoracic esophagectomy and end cervical esophagostomy, we elected to perform an end thoracic esophagostomy to avoid an esophagectomy. Subsequently, we were able to reconstruct her gastrointestinal continuity using her native esophagus. Her functional result was quite good (Figure 2).

There are really no good options for reconstruction in patients requiring total gastrectomy who cannot under go primary reconstruction. Esophagectomy and end cervical esophagostomy is an option. To reconstruct this requires a colon interposition or jejunum in a long Roux-en-Y loop or use of a supercharged free jejunal interposed graft. Neither of these options were possible in the infant we present, nor were they deemed viable options in the elderly woman with multiple intercurrent illnesses. Another option would be to leave the esophagus in the posterior mediastinum 
closed at the end as a blind pouch, which leads to blowout of the closed end of the esophagus unless it is done in conjunction with a loop cervical esophagostomy. Loop cervical esophagostomy often leads to esophageal dysfunction stricture at the stoma, dysphagia, and aspiration. ${ }^{1}$ Retrograde esophageal intubation is another option that will preserve esophageal length for delayed reconstruction and avoids the need for a cervical esophagostomy. ${ }^{2}$ This technique presented in 2 patients requires an indwelling percutaneous Ewald tube to establish a controlled esophagocutaneous fistula. It requires a long-standing percutaneous tube and allows ongoing contamination of the mediastinum. The approach we present has the advantage of preserving esophageal length without the need for a long-standing percutaneous tube and avoids ongoing mediastinal contamination.

\section{References}

1. Orringer MB. Reversing esophageal discontinuity. Semin Thorac Cardiovasc Surg. 2007; 19:47-55.

2. O'Connor JV, Scalea TM. Retrograde esophageal intubation. Am Surg. 2007;73: 267-70.

\title{
Adjusting the length of artificial polytetrafluoroethylene chordae in mitral valve repair by a single loop technique
}

\author{
Narain Moorjani, FRCS (C-Th), ${ }^{\mathrm{a}}$ Nicola Viola, MD, ${ }^{\mathrm{a}}$ Vilius Janusauskas, MD, ${ }^{\mathrm{b}}$ and Steven Livesey, FRCS, \\ Southampton, United Kingdom, and Vilnius, Lithuania
}

Obtaining the exact length of artificial chordae used in the surgery of anterior mitral valve prolapse can be difficult. In this report, a simple, reproducible method of artificial chordae implantation is described using a single loop technique.

\section{SURGICAL TECHNIQUE}

A horizontal mattress suture with pledget-supported CV-4 polytetrafluoroethylene (PTFE; Gore-Tex suture; W. L. Gore \& Associates, Inc, Flagstaff, Ariz) is initially placed through the fibrous thickened part of the appropriate papillary muscle. Both ends of the suture are then passed through the prolapsing scallop 3 to $5 \mathrm{~mm}$ from the free edge of the leaflet from the ventricular side to the atrial side (Figure 1, $A)$. The greater distance from the free edge is used when there is an excessive amount of tissue, as this produces a rolling effect that reduces the leaflet length and the risk of systolic anterior motion of the mitral valve. One of the suture ends is then passed through the leaflet edge again from ventricular side to atrial side to produce a single loop (Figure 1, $A$ ). Additional PTFE sutures are implanted as appropriate to

\footnotetext{
From the Department of Cardiothoracic Surgery, Southampton General Hospital, ${ }^{\text {a }}$ Southampton, United Kingdom, and the Department of Cardiac Surgery, Vilnius University, ${ }^{\mathrm{b}}$ Vilnius, Lithuania.

Received for publication May 5, 2008; accepted for publication May 26, 2008; available ahead of print Feb 7, 2009.

Address for reprints: Narain Moorjani, FRCS (C-Th), c/o Mr Steven Livesey's secretary, Department of Cardiothoracic Surgery, Southampton General Hospital, Southampton, SO16-6YD, United Kingdom (E-mail: narain.moorjani@doctors.org.uk). J Thorac Cardiovasc Surg 2009;138:1441-2

$0022-5223 / \$ 36.00$

Copyright (c) 2009 by The American Association for Thoracic Surgery

doi:10.1016/j.jtcvs.2008.05.071
}

the number of prolapsing scallops of the anterior and posterior mitral valve leaflets. After sizing of the mitral annulus, an annuloplasty ring (Physio or Cosgrove, Edwards Lifesciences, Irvine, Calif) is implanted with interrupted 2-0 Ethibond sutures (Ethicon, Inc, Somerville, NJ). Valve competency is then tested by injecting cold saline into the left ventricle across the valve (Figure 1,B). With the left ventricle full, the correct height of the neochordae can be easily adjusted to ensure good leaflet coaptation and demonstrate areas of regurgitation and residual prolapse (Figure 1,C). This process is repeated by adjusting the chordal length until the valve is fully competent (Figure 1, D). Each PTFE suture is then passed through the leaflet edge once more to reduce the risk of overtightening the suture when tying, thereby reducing the chordal height (Figure 1,E). This technique of using saline distention of the left ventricle allows the chordae to be sized and subsequently tied at as near physiologic loading conditions as it is possible to recreate in the arrested heart. Before the left atrium is closed, the mitral valve leaflets are observed to be bulging with appropriate areas of coaptation and no residual regurgitation or prolapse (Figure $1, F)$. Where appropriate, data are presented as mean \pm standard error of mean.

\section{RESULTS}

Between March 2006 and December 2007, 56 patients (38 male, 18 female, with a mean age of $61.2 \pm 2.1$ years) underwent artificial PTFE chord implantation to treat mitral valve leaflet prolapse. In patients with bileaflet prolapse $(\mathrm{n}=34), 3.4 \pm 0.2$ (range, 1-6) PTFE chordae were 